\title{
Genetic Diversity of Rhubarb Cultivars
}

\author{
Joseph C. Kuhl ${ }^{1}$ and Veronica L. DeBoer \\ U.S. Department of Agriculture, Agricultural Research Service, Subarctic Agricultural Research \\ Unit, Palmer, AK 99645-6629
}

AdDitional INDEX wORDs. Rheum, R. rhabarbarum, culinary, genetic distance, AFLP

\begin{abstract}
The genus Rheum L., commonly known as rhubarb, is composed of $\approx 60$ species, primarily distributed throughout northern and central Asia. Rhubarb species have been used for medicinal purposes for thousands of years; however, it was not until the 18th century that the culinary use of petioles was first reported. Although the origin(s) of culinary rhubarb is not clear, it is thought that they originated from hybridization of rhubarb species originally brought to Europe for medicinal purposes. Most rhubarb cultivars lack pedigree information, and the genetic relationship among cultivars is largely unknown. Amplified fragment length polymorphism (AFLP) markers were generated for fingerprint analysis of 37 cultivars and four putative Rheum species accessions. Ten EcoRI and MseI primer combinations were analyzed for a total of 1400 scored polymorphisms, with an average of 140 polymorphisms per primer combination. Results show at least two clusters of related cultivars, as well as distantly related accessions. This study provides an estimate of rhubarb cultivar genetic diversity using AFLP analysis.
\end{abstract}

The genus Rheum (Polygonaceae), commonly known as rhubarb, is composed of $\approx 60$ species, primarily distributed in mountainous and desert regions of northern and central Asia (Wang et al., 2005). For thousands of years, rhubarb has been used in China for medicinal purposes. In the middle of the 17th century, rhubarb species began to be grown in Europe for medical uses (Foust, 1992; Turner, 1938). At the beginning of the 18th century, it was discovered that rhubarb had edible stalks (Foust, 1992). Growers, primarily in England, started to develop culinary Rheum rhabarbarum L. cultivars, including the still common cultivars Victoria and Prince Albert (Turner, 1938). Early culinary cultivars were selected from openpollinated seed of rhubarb species. It is believed that Rheum rhaponticum L., Rheum undulatum L. (also referred as $R$. rhabarbarum), and Rheum palmatum L. were involved in hybridizations, although pedigrees are mostly absent from these early open pollinations (Foust and Marshall, 1991; Morse, 1901; Turner, 1938). Culinary rhubarb is generally considered a tetraploid, $2 \mathrm{n}=44$; however, rhubarb species are $2 \mathrm{n}=22,44$, and 66 (Chin and Youngken, 1947; Englund, 1983). Today, the origin of culinary rhubarb is still unclear; however, many culinary cultivars have been identified for a wide range of uses from tarts to wine, resulting in a plethora of phenotypes. The term cultivar from here on in this article will refer to culinary rhubarb cultivars.

Rhubarb cultivars are ideally propagated asexually by planting crown divisions (Zandstra and Marshall, 1982) or through micropropagation (Walkey and Mathews, 1979), thereby generating putatively identical genotypes. The propagation of seed is discouraged because progeny are not necessarily true to type; however, propagation by seed still occurs. Self-sterile and selffertile genotypes have been reported (Rumpunen, 1996). This raises the possibility that some cultivars, if propagated by seed, may generate progeny more true to self than others, such that

Received for publication 12 Feb. 2008. Accepted for publication 29 Apr. 2008. The reported use of brand name products does not imply an endorsement by the U.S. Department of Agriculture.

Many thanks to Dale E. Marshall for acquiring the collection, donating it to the National Plant Germplasm System, and for his notes and thoughts on the collection.

${ }^{1}$ Corresponding author. E-mail: ffjck@uaf.edu. multiple seedlings of a cultivar might appear relatively uniform (as from asexual propagation) but be the product of selffertilization. Propagation of culinary cultivars by seed would result in a range of genotypes with the same name. Conversely, cultivars with different names may be the same. Turner (1938) lists numerous cases of the same cultivar appearing under different names. 'Early Red' was notably grown under a dozen names. In general, pedigree information about cultivars is missing or never recorded, making cultivar identification difficult and nearly impossible to authenticate.

Cultivar identification has primarily relied on morphology; however, such traits are influenced by environmental factors (Persson et al., 2000). Persson et al. (2000) used the randomly amplified polymorphic DNA (RAPD) method and morphology to characterize 12 cultivars. Moderate correlation was found between the two methods. AFLP detects loci throughout a genome by selective amplification of restriction fragments (Vos et al., 1995). Amplified fragment length polymorphism (AFLP) analysis does not require prior knowledge of an organism's genome (Vos et al., 1995) and has been widely shown to be reproducible (Jones et al., 1997). AFLP profiles have the possibility to generate a large number of polymorphisms (Han et al., 2000; Kim et al., 2004; Tamiru et al., 2007) and have been widely used to determine cultivar relationships and cultivar identification (Jubrael et al., 2005; Parks and Moyer, 2004; Parks et al., 2006). AFLP analysis has been shown to excel at estimating genetic diversity compared with morphological traits (Roy et al., 2004).

The objective of this study was to apply the AFLP technique to assess the genetic variability between selected culinary rhubarb cultivars and rhubarb species to determine genetic relationships and genetic diversity.

\section{Materials and Methods}

Plant Material. Plant material for this study came from the U.S. Department of Agriculture (USDA), Agricultural Research Service (ARS) National Plant Germplasm System Rheum collection, which is maintained at the Subarctic Agricultural Research Unit in Palmer, AK. The majority of culinary rhubarb and rhubarb species accessions in the collection 
originated from the D.E. Marshall collection at Michigan State University (MSU), East Lansing. The collection was established in Palmer, AK, in 2001 from crown pieces. Primary notes and records for culinary cultivars and rhubarb species accessions from D.E. Marshall and the original MSU plot numbers (MSU no.) are referenced in Table 1.
AFLP ANALysis. Thirty-seven culinary cultivars and four putative Rheum species accessions were sampled from the germplasm collection in Palmer, AK (Table 1). Tissue from emerging leaves was collected from single plants of each accession, with the exception of 'German Wine', where two plants, 9 and 27, were sampled. Leaf tissue was also collected

Table 1. Identification numbers (ID no.) for Rheum accessions evaluated in this study. Germplasm can be referenced by arctic germplasm number (AG no.) in the Germplasm Resources Information Network (GRIN). The original Michigan State University plot numbers (MSU no.) and sources are included to help distinguish similarly named cultivars.

\begin{tabular}{|c|c|c|c|c|c|c|}
\hline ID no. & Accession & AG no. & Species & MSU no. & Source $^{z}$ & Province, country ${ }^{\mathrm{y}}$ \\
\hline 1 & R. palmatum $2 / 42 \mathrm{UK}^{\mathrm{x}}$ & Not in GRIN & R. palmatum & - & $\mathrm{n} / \mathrm{a}$ & $\mathrm{n} / \mathrm{a}$ \\
\hline 3 & Johnson's St. Martin 426/27 & AG 1231 & R. rhabarbarum & 50 & University of Minnesota $^{\mathrm{w}}$ & Minnesota, USA \\
\hline 6 & Ruby $201 / 29$ & AG 1161 & R. rhabarbarum & 44 & University of Minnesota & Minnesota, USA \\
\hline 7 & Plum Hutt & AG 1169 & R. rhabarbarum & 16 & University of Minnesota & Minnesota, USA \\
\hline 8 & Linnaeus $137 / 31$ & AG 1165 & R. rhabarbarum & 51 & University of Minnesota & Minnesota, USA \\
\hline 11 & Penn State \#3 & AG 1212 & R. rhabarbarum & 57 & University of Minnesota & Minnesota, USA \\
\hline 12 & Crimson Red & AG 1213 & R. rhabarbarum & 109 & Ahrens Nursery & Indiana, USA \\
\hline 13 & Timperly Early & AG 1214 & R. rhabarbarum & 56 & $\begin{array}{l}\text { Stockbridge House Exp'l } \\
\text { Hort Station }\end{array}$ & North Yorkshire, UK \\
\hline 14 & Sutton (MSU 17) & AG 1215 & R. rhabarbarum & 17 & Lennox Farms & Ontario, Canada \\
\hline 18 & New Zealand & AG 1219 & R. rhabarbarum & 5 & Kelburn Holdings, Ltd. & Canterbury, New Zealand \\
\hline 19 & Cawood Delight & AG 1221 & R. rhabarbarum & 74 & Nourse Farms, Inc. & Massachusetts, USA \\
\hline 20 & The Sutton (MSU 64) & AG 1222 & R. rhabarbarum & 64 & $\mathrm{n} / \mathrm{a}$ & $\mathrm{n} / \mathrm{a}$ \\
\hline 21 & R. officinale & AG 1223 & R. officinale & 40 & University of Minnesota & Minnesota, USA \\
\hline 22 & Cherry Red & AG 1225 & R. rhabarbarum & 23 & Carl Nitz & Michigan, USA \\
\hline 23 & Prince Albert & AG 1226 & R. rhabarbarum & 52 & Lennox Farms & Ontario, Canada \\
\hline 24 & Canada Red & AG 1227 & R. rhabarbarum & 72 & Krieger Wholesale Nursery & Michigan, USA \\
\hline 25 & McDonald & AG 1228 & R. rhabarbarum & 71 & Krieger Wholesale Nursery & Michigan, USA \\
\hline 26 & MacDonald & AG 1229 & R. rhabarbarum & 112 & Nourse Farms, Inc. & Massachusetts, USA \\
\hline 27 & Coulter McDonald & AG 1230 & R. rhabarbarum & 69 & University of Minnesota & Minnesota, USA \\
\hline 28 & German Wine $^{\mathrm{v}}$ & AG 1232 & R. rhabarbarum & 48 & Agriculture Canada & Nova Scotia, Canada \\
\hline 36 & Rheum palmatum Rubra & AG 1203 & R. palmatum & 39 & University of Minnesota & Minnesota, USA \\
\hline 37 & Mammoth & AG 1239 & R. rhabarbarum & 62 & University of Minnesota & Minnesota, USA \\
\hline 38 & Crimson Wine 115/55 & AG 1204 & R. rhabarbarum & 33 & University of Minnesota & Minnesota, USA \\
\hline 39 & Crimson Delicious 136/30 & AG 1202 & R. rhabarbarum & 65 & University of Minnesota & Minnesota, USA \\
\hline 45 & Sutton (MSU 22) & AG 1201 & R. rhabarbarum & 22 & $\begin{array}{l}\text { Michigan Quality } \\
\text { Frozen Foods }\end{array}$ & Michigan, USA \\
\hline 46 & Crimson Cherry & AG 1240 & R. rhabarbarum & 110 & J. G. Meier \& Sons & Kansas, USA \\
\hline 50 & Loher Blut & AG 1250 & R. rhabarbarum & 41 & $\mathrm{n} / \mathrm{a}$ & $\mathrm{n} / \mathrm{a}$ \\
\hline
\end{tabular}

${ }^{\mathrm{z}}$ Source of germplasm donated to the D.E. Marshall collection.

${ }^{\mathrm{y}}$ Location of source.

${ }^{\mathrm{x}}$ Not part of the original D.E. Marshall collection.

${ }^{w}$ All University of Minnesota accessions donated by D. Davis.

'Two 'German Wine' plants, 9 and 27, were evaluated with 10 primer combinations. 
from 30 individual plants of 'German Wine', which visually sorted into two phenotypic groups, 14 plants with small darkcolored leaves, and 16 plants with larger, light-colored leaves; plants 9 and 27 typify these two phenotypes, respectively. Genomic DNA was isolated using the DNeasy Plant DNA isolation kit (Qiagen, Valencia, CA) according to manufacturer guidelines.

AFLP analysis was conducted using a modified procedure based on Vos et al. (1995). The sequence of adapters and primers was described by Kim et al. (2004) with the exception of selective primers (Table 2), and was generated by Integrated DNA Technologies (Coralville, IA). EcoRI selective primers were labeled with WellRED D4, a blue phosphoramidite dye. In the restriction and ligation reaction, genomic DNA (500 ng) was incubated at $37^{\circ} \mathrm{C}$ for $14 \mathrm{~h}$ with $1 \times \mathrm{T} 4$ ligase buffer (with ATP), $50 \mathrm{~mm} \mathrm{NaCl}, 5 \mathrm{U}$ of MseI and EcoRI, $5 \mu \mathrm{MMseI}$ adapter, $1 \mu \mathrm{M} E c o$ RI adapter, and $1 \mathrm{U}$ of T4 DNA ligase. Preamplification was performed using $M s e \mathrm{I}+\mathrm{C}$ and $E c o \mathrm{RI}+\mathrm{A}$ primers. The reaction mixture contained $3 \mu \mathrm{L}$ of $10 \times$ diluted restriction and ligation template DNA, $1 \times$ polymerase chain reaction $(\mathrm{PCR})$ buffer (with $2.0 \mathrm{~mm} \mathrm{MgCl}_{2}$ ), $0.2 \mathrm{~mm}$ each dNTPs, $0.3 \mu \mathrm{m}$ each of two primers, and $0.5 \mathrm{U}$ of Taq polymerase for a total volume of $13 \mu \mathrm{L}$. Preamplification cycle conditions were performed according to Kim et al. (2004). Selective amplification reactions (an $8-\mu \mathrm{L}$ volume) contained $2 \mu \mathrm{L}$ of $10 \times$ diluted preselective template DNA, $1 \times$ PCR buffer (with $2.0 \mathrm{~mm}$ $\mathrm{MgCl}_{2}$ ), $0.2 \mathrm{~mm}$ each dNTPs, $0.625 \mu \mathrm{m}$ each of the two selective primers, and $0.2 \mathrm{U}$ of $\mathrm{Taq}$ polymerase. Selective amplification PCR conditions consisted of an initial denaturation step of $2 \mathrm{~min}$ at $94{ }^{\circ} \mathrm{C}, 20 \mathrm{~s}$ at $94{ }^{\circ} \mathrm{C}, 30 \mathrm{~s}$ at $66{ }^{\circ} \mathrm{C}$, and $2 \mathrm{~min}$ at $72{ }^{\circ} \mathrm{C}$; the annealing temperature was then lowered $1{ }^{\circ} \mathrm{C}$ each cycle for the next nine cycles followed by 25 cycles at $94{ }^{\circ} \mathrm{C}$ for $30 \mathrm{~s}, 56^{\circ} \mathrm{C}$ for $30 \mathrm{~s}$, and $72{ }^{\circ} \mathrm{C}$ for $3 \mathrm{~min}$, finishing with $60^{\circ} \mathrm{C}$ for $30 \mathrm{~min}$. After selective amplification, $1 \mu \mathrm{L}$ of reaction product was mixed with $35 \mu \mathrm{L}$ of sample loading solution plus $0.5 \mu \mathrm{L}$ of $600-\mathrm{bp}$ size standard from Beckman Coulter (Fullerton, CA).

Samples were separated using capillary electrophoresis on an automated CEQ 8800 Genetic Analysis System (Beckman Coulter). Fragments were automatically sized and placed in bins. Each fragment (bin) was scored as present (1) or absent (0) using CEQ 8800 software (version 9.0). Inclusion or exclusion of fragments was determined by adjusting the ratio of the relative peak height threshold (RPHT) to the slope threshold (ST). A preliminary fragment list was generated using RPHT:ST $=10: 10$ and was compared with the 10:1 fragment list (Table 2). Discrepancies were manually evaluated by visually checking the electropherograms. When greater than $10 \%$ of the samples showed discrepancies, the bin was eliminated; less than $10 \%$, and bins were corrected according to visual evaluation.

In a preliminary test, 64 primer combinations were screened on 'Reeds Early Superb' to identify suitable selective primer combinations based on maximum $Y$ values, number of peaks, and peak clustering. Sixteen selective primer combinations were identified, 10 of which ultimately proved the most efficacious for the majority of accessions analyzed (Table 2). These 10 primer combinations were applied to 37 cultivars, including two individuals of 'German Wine' (plants 9 and 27), and four rhubarb species. Thirty 'German Wine' individuals (plants 1-30) were evaluated with two primer combinations, MCTC/E-ACA and M-CAG/E-ACT. Plant 6 was dropped due to low dye signal.

Data analysis. Phenetic analysis was conducted using NTSYS-pc (version 2.20e; Applied Biostatistics, Setauket, NY). Distance matrices (SIMQUAL) were generated using Dice (1945) estimate of genetic similarity (equivalent to Nei and $\mathrm{Li}, 1979)$, an appropriate coefficient for a predominately dominant marker (Parks and Moyer, 2004). For comparative purposes, distance matrices using Jaccard's similarity coefficient were generated. Clustering was performed using Dice's similarity coefficients and the unweighted pair group method (UPGMA), with the "FIND" option enabled to detect all possible trees. The COPH and MXCOMP modules of NTSYS calculated the goodness of fit of the clustering to the data matrix. Internal branch support was evaluated by bootstrap analysis of 1000 bootstrap replicated data sets with Phylogenetic Analysis Using Parsimony (version 4.0b10; Sinauer Associates, Sunderland, MA). Cultivar relationships were also studied using principal coordinates analysis (PCO). Dice's similarity coefficient and NTYSYS-pc modules DCENTER, EIGEN, and MXPLOT were used to generate two-dimensional analyses.

Table 2. Scored polymorphisms of 10 AFLP primer combinations applied to 37 rhubarb cultivars and four rhubarb species.

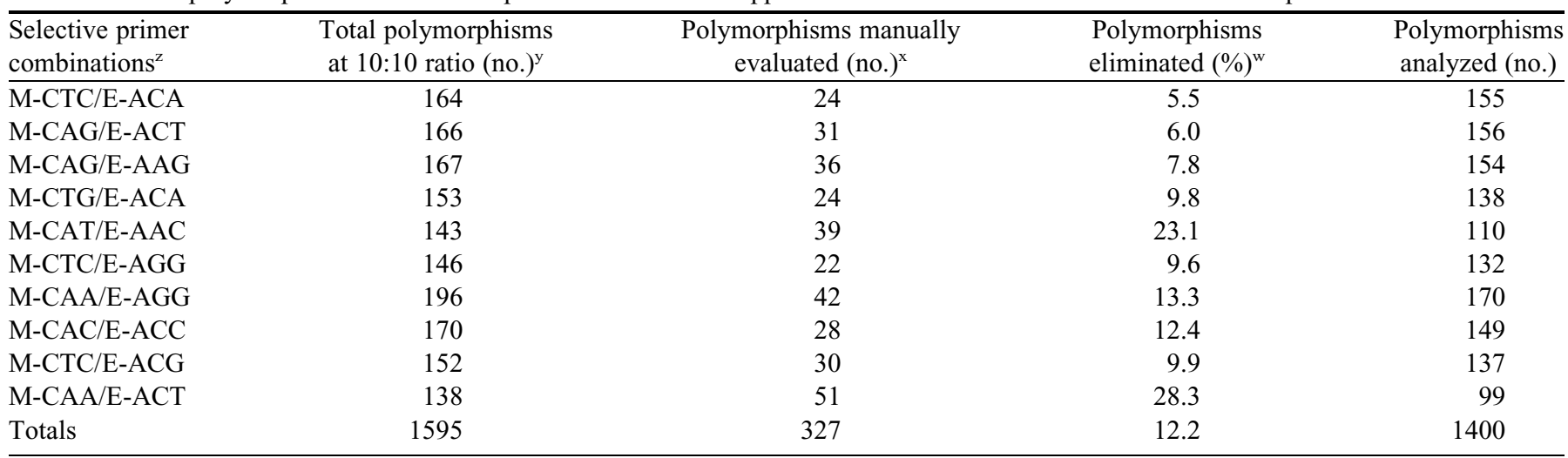

${ }^{\mathrm{z}} M s e \mathrm{I}+3 / E c o \mathrm{RI}+3$ primers, EcoRI primers labeled with WellRED D4, a blue phosphoramidite dye.

${ }^{\mathrm{y}}$ Total number of polymorphisms at a 10:10 ratio of the relative peak height threshold to the slope threshold.

${ }^{x}$ Number of polymorphisms showing discrepancies when comparing 10:10 and 10:1 ratios.

${ }^{w}$ Percentage of total polymorphisms (10:10 ratio) eliminated by manual scoring. 


\section{Results}

AFLP Results. A total of 1400 AFLP polymorphisms was scored for 37 cultivars and four rhubarb species using $10 \mathrm{Mse} /$ EcoRI primer combinations. The number of scored polymorphisms per primer combination ranged from 99 to 170 , for an average of 140 scored fragments per primer combination. Each primer combination generated an average of 38 fragments per sample, with 'Linnaeus 137/31' averaging 29 and 'Chipman' 54, minimum and maximum average fragments per primer combination, respectively. Scored fragments ranged from 56 to $627 \mathrm{bp}$ with a mean of $200 \mathrm{bp}$ and a median of $181 \mathrm{bp}$. Analysis of 29 'German Wine' plants with M-CTC/E-ACA and M-CAG/ E-ACT resulted in 317 scored polymorphisms compared with 311 for the same two primer combinations in the larger dataset.

GenetiC Distance anAlysis. Dice's similarity coefficient (Nei and Li, 1979) averaged between all cultivars and four Rheum accessions was 0.665 , and among cultivars was 0.683 . The average genetic distance of $R$. palmatum $2 / 42$ UK with all other samples was 0.463 , and was 0.467 among cultivars, suggesting it as a putative outgroup. The average genetic distances for the other three putative Rheum species accessions with cultivars was $0.649,0.577$, and 0.667 , Rheum UK Lot 540533, Rheum officinale Baill., and R. palmatum 'Rubra,' respectively. The average genetic distance between 'Cawood Delight' and other cultivars was 0.466 . The pairwise similarity coefficient between the two $R$. palmatum accessions, $R$. palmatum 2/42, and $R$. palmatum 'Rubra', was 0.483 . The highest similarity coefficient, 0.901, was between 'German Wine' (plant 27) and 'Sutton' (MSU 22), and the lowest, 0.396, was between 'Cawood Delight' and 'OR23'. The similarity coefficient between 'German Wine' plants 9 and 27 was 0.755 .

A dendrogram was constructed using Dice's similarity coefficient and the UPGMA method (Fig. 1). The cophenetic correlation coefficient was 0.92 between the clustering and the data matrix. A bootstrap value of 100 separated $R$. palmatum $2 / 42$ UK and 'Cawood Delight' from the other cultivars and the three putative Rheum species accessions. Highly significant bootstrap values $(\geq 90)$ were detected for six groups of cultivars. The two largest groups included five cultivars clustered with 'Victoria 574/27' and six cultivars clustered with 'Sutton' (MSU 17), bootstrap values 99 and 100, respectively. Pairwise similarity coefficients for the "Victoria 574/ 27 ' group ranged from 0.764 to 0.849 , with an average of 0.812 , whereas the 'Sutton' group ranged from 0.804 to 0.901 , with an average of 0.861 . The two 'German Wine' plants were clearly separated, with plant 27 tightly clustered with 'Sutton' (MSU 22) and plant 9 clustered with 'Cherry Red'. Rheum palmatum 'Rubra' was nested among the cultivars. Analysis of the 29 'German Wine' individuals resulted in two clusters represented by plants 9 and 27 (Fig. 2). All individuals of a phenotypic class clustered with like individuals in the dendrogram (data not shown).

Principle coordinates analysis (PCO) of the AFLP-based distance data were performed to provide additional resolution. The first and second principal coordinates described $\approx 9 \%$ and $7 \%$ of the total variation, respectively (Fig. 3). As shown in the dendrogram, PCO clearly separates $R$. palmatum 2/42 UK (ID no. 1) and 'Cawood Delight' (ID no. 19) from all other samples. Similarly, the six cultivars in the 'Sutton' (MSU 17) branch of the dendrogram cluster on the left edge of the PCO, although 17 is separated from the rest. Contrasting with the UPGMA dendrogram, the PCO separates samples 12, 21, 25, and 34 from the primary distribution, 'Crimson Red', $R$. officinale, 'McDonald', and 'Chipman', respectively.

\section{Discussion}

This is the first report of AFLP marker analysis in culinary rhubarb. A large number of polymorphisms was scored, with an average of 140 per primer combination. This is similar to 184 fragments per primer combination reported by Kim et al. (2004). Other AFLP studies (Carr et al., 2003; Han et al., 2000; Tamiru et al., 2007) have scored large numbers of polymorphisms, and it is recognized that automated fluorescent-dye capillary electrophoresis-based AFLP is particularly well suited for detecting fragments (Alonso-Blanco et al., 1998; Schmidt and Jensen, 2000). To maintain the highest quality possible, efforts were made to conservatively determine fragments for scoring in this study by using stringent criteria for peak determination.

AFLP analysis was able to distinguish all cultivars and rhubarb species. In Fig. 1, six cultivars, including 'Sutton' (MS 17), cluster together with a bootstrap value of 100 . Three of the six cultivars are called 'Sutton' (MSU 17, MSU 22, and MSU

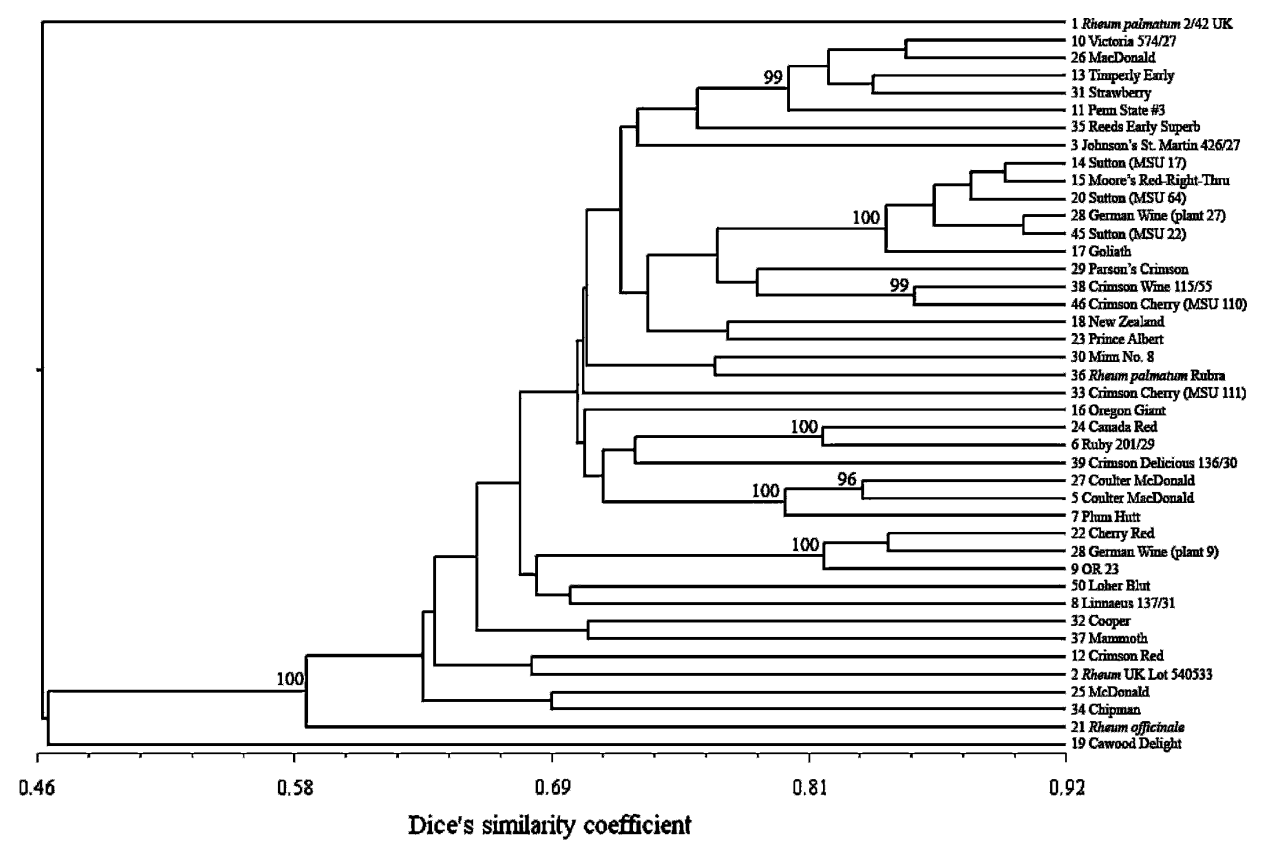

Fig. 1. Dendrogram of 37 culinary rhubarb cultivars and four rhubarb species using 1400 AFLP polymorphisms, generated using Dice's similarity coefficient and UPGMA clustering. Numbers at the nodes are bootstrap values for 1000 replications, showing those greater than or equal to 90 . 


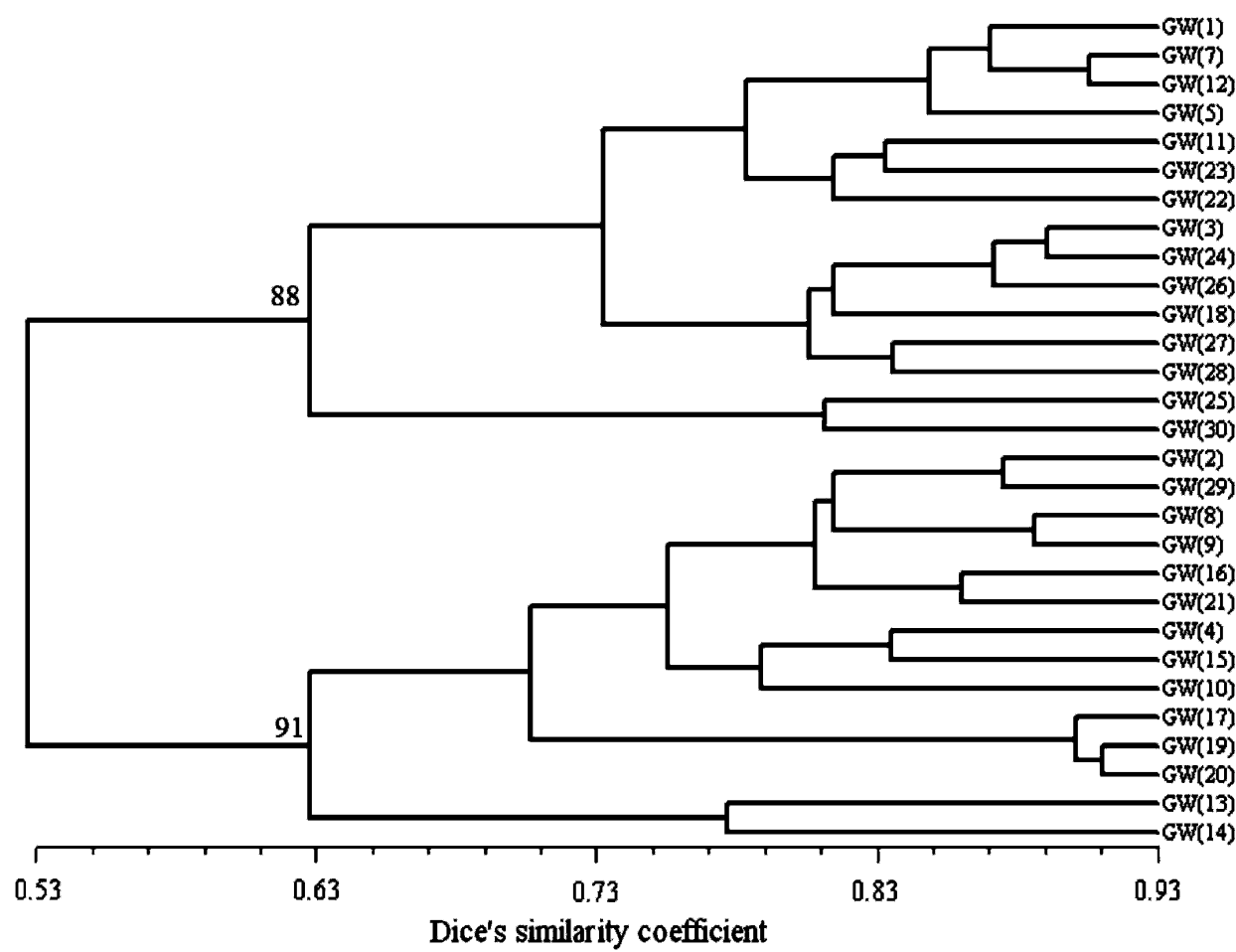

Fig. 2. Dendrogram of 29 'German Wine' (GW) plants from two AFLP primer combinations, 317 scored polymorphisms, generated using Dice's similarity coefficient and UPGMA clustering. Numbers at the nodes are bootstrap values for 1000 replications. The two branches denoted by bootstrap values separate the two 'German Wine' phenotypes.

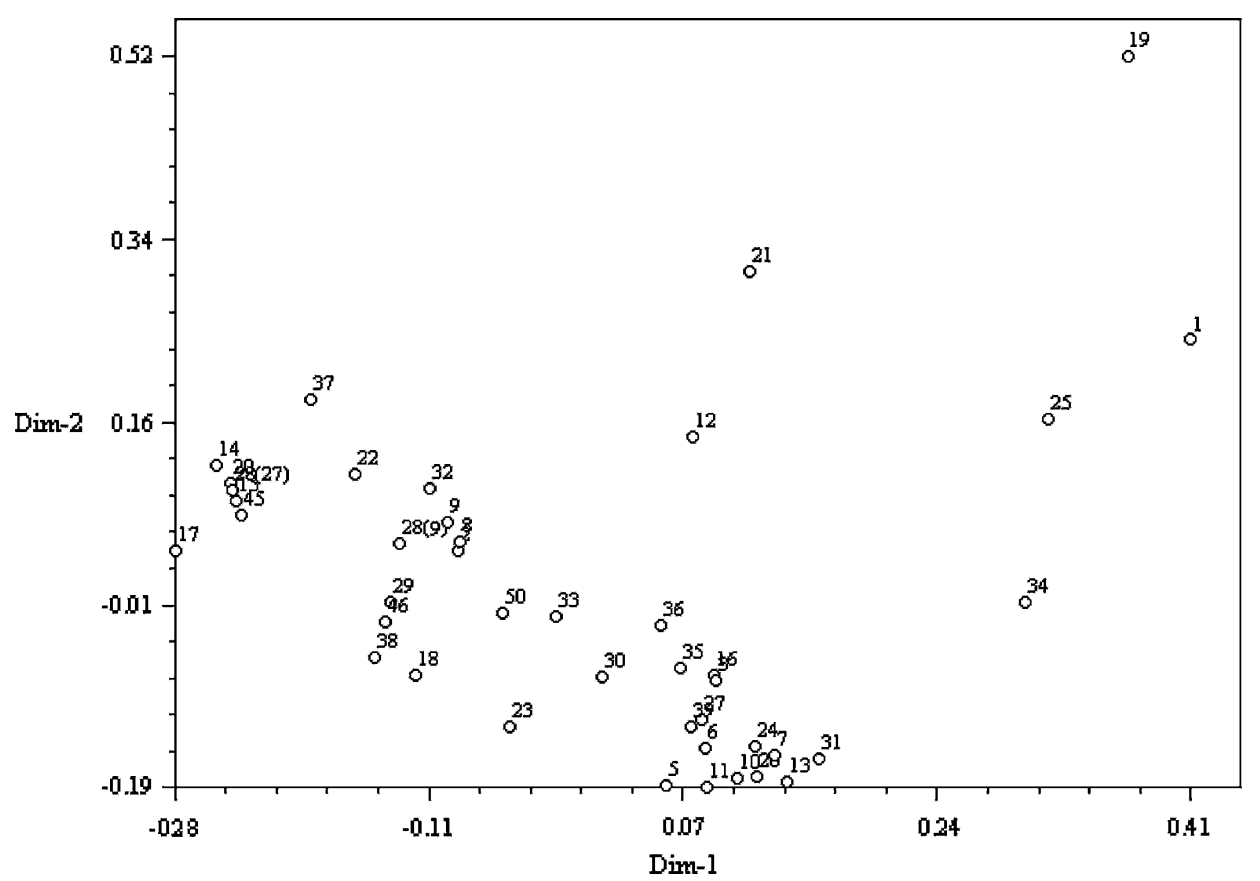

Fig. 3. Two dimensional (Dim) principal coordinates analysis of 37 rhubarb cultivars and four rhubarb species using 1400 AFLP polymorphisms and Dice's similarity coefficient.

64), which have been kept separate to determine if a cultivar from a wide variety of sources would show differences (D.E. Marshall, personal communication). 'Moore's Red-RightThru', originally from Agriculture Canada, is reported to be a selection from 'Sutton'. The other two cultivars, German Wine (plant 27) and Goliath, lack pedigree information. All six of these cultivars are closely related, with an average similarity distance of 0.861 . If all of these were clonally propagated from a common source, genetic variability is not expected; however, Smith et al. (2007) report $\approx 10 \%$ variability between individual plants of asexually propagated flowering dogwood (Cornus florida L.) cultivars using AFLPs. They propose that the variability may reflect inherent variations in the AFLP technique, such that diversity levels among duplicate trees may be due to noise in the system. The two most prevalent AFLP errors are allele homoplasy and scoring errors (Bonin et al., 2007). Allele homoplasy-when nonhomologous fragments migrate at the same position-tends to inflate similarity values, decreasing diversity estimates. However, scoring errors could lead to inflated diversity, but as described, the above efforts were made to limit scoring errors. Conversely, the detected variability may be real. Ellstrand and Roose (1987) identify clonal populations with variability similar to nonclonal plants. Similarly, Chen et al. (2004) detected unexpected variability among sports and somaclonal variants of cultivated Dieffenbachia Schott. Regardless, AFLP results here clearly show that these six cultivars are closely related, and are partially confirmed by available source data. A similar statement could be made about the "Victoria $574 / 27$ ' cluster of five cultivars. It is likely that all of these cultivars are related to 'Victoria' originally released by Joseph Myatt Manor Farm in 1837 (Turner, 1938). 'Victoria 574/ 27 ' was a selection from 'Victoria' (reportedly released in England in 1903). Another dendrogram branch (bootstrap 100) clusters 'Coulter McDonald', 'Coulter MacDonald', and 'Plum Hutt' together. All three are from the University of Minnesota, originating from the Morden Experiment Station, Morden, Canada, suggesting a common lineage.

The accession 'German Wine' was almost equally divided into two clear phenotypes, 16 and 14 plants each. Analysis of 29 individuals with two primer pairs precisely groups them into the two phenotypes (Fig. 2). Inclusion of two plants, 9 and 27, in the original study with 10 primer combinations confidently links 
them to 'Cherry Red' and 'Sutton' (MSU 22), respectively. As mentioned above, these two lines may reflect divergent genotypes arising from clonal propagation. It is also possible that over many years of propagation, mishandling of crowns has resulted in a mixed line. Another possibility is the two phenotypes arose from open-pollinated seed; however, this is difficult to resolve without putative parental lines. Until additional data are generated, the two 'German Wine' lines will be grouped together under one name while recognizing phenotypic and genotypic divergence.

Lack of provenance for the four Rheum accessions confounds efforts to interpret the relationship of $R$. palamatum and $R$. officinale to culinary rhubarb. Accession $R$. palmatum 2/42 UK clearly diverges from the cultivars analyzed here. Contrasting this is $R$. palmatum 'Rubra', which falls in the middle of the cultivars and has an average similarity coefficient of 0.667 with the cultivars compared with the average similarity among cultivars of 0.683 . This accession possibly represents an example of open pollination of a wild $R$. palmatum with a culinary-type rhubarb. Rheum palmatum $2 / 42$ UK is morphologically similar to $R$. palmatum and is unlikely a hybrid with an unrelated species. Rheum officinale (ID no. 21) in the PCO clearly separates from the central set of cultivars; however, it falls within the central group on the dendrogram, albeit somewhat distantly related. Interestingly, 'Cawood Delight', a cultivar from Cawood Selby, North Yorkshire, England, like R. palmatum $2 / 42 \mathrm{UK}$, falls outside the central set of cultivars in the dendrogram and PCO. This suggests a source of diversity rare among cultivars in this study. Dice's average similarity coefficient of 'Cawood Delight' among cultivars is 0.466 and has the lowest similarity coefficient with 'OR23', at 0.396 , or Jaccard's similarity coefficient 0.247 . This is higher than the lowest value reported by Persson et al. (2000) between two cultivars, Jacarrd's similarity coefficient 0.130 , suggesting that the collection may be lacking cultivars with more diverse backgrounds. It would be useful to identify additional cultivars with a common background to 'Cawood Delight'.

\section{Literature Cited}

Alonso-Blanco, C., A.J.M. Peeters, M. Koornneef, C. Lister, C. Dean, N. van den Bosch, J. Pot, and M.T.R. Kuiper. 1998. Development of an AFLP based linkage map of Ler, Col and Cvi Arabidopsis thaliana ecotypes and construction of a Ler/Cvi recombinant inbred line population. Plant J. 14:259-271.

Bonin, A., D. Ehrich, and S. Manel. 2007. Statistical analysis of amplified fragment length polymorphism data: A toolbox for molecular ecologist and evolutionists. Mol. Ecol. 16:3737-3758.

Carr, J., M. Xu, J.W. Dudley, and S.S. Korban. 2003. AFLP analysis of genetic variability in new guinea impatiens. Theor. Appl. Genet. 106:1509-1516.

Chen, J., R.J. Henny, D.J. Norman, P.S. Devanand, and C.T. Chao. 2004. Analysis of genetic relatedness of Dieffenbachia cultivars using AFLP markers. J. Amer. Soc. Hort. Sci. 129:81-87.

Chin, T.C. and H.W. Youngken. 1947. The cytotaxonomy of Rheum. Amer. J. Bot. 34:401-407.

Dice, L.R. 1945. Measures of the amount of ecological association between species. Ecology 26:297-302.

Ellstrand, N.C. and M.L. Roose. 1987. Patterns of genotypic diversity in clonal plant species. Amer. J. Bot. 74:123-131.

Englund, R. 1983. Odlad rabarber och taxonomiska problem inon släktet Rheum speciellt sektionen Rhapontica. Report, Dept. of Systematic Botany, Uppsala University, Uppsala, Sweden.

Foust, C.M. 1992. Rhubarb: The wondrous drug. Princeton University Press, Princeton, NJ.
Foust, C.M. and D.E. Marshall. 1991. Culinary rhubarb production in North America: History and recent statistics. HortScience 26:1360-1363. Han, T., M. de Jeu, H. van Eck, and E. Jacobsen. 2000. Genetic diversity of Chilean and Brazilian Alstroemeria species assessed by AFLP analysis. Heredity 84:564-569.

Jones, C.J., K.J. Edwards, S. Castaglione, M.O. Winfield, F. Sala, C. van de Wiel, G. Bredemeijer, B. Vosman, M. Matthes, A. Daly, R. Brettschneider, P. Bettini, M. Buiatti, E. Maestri, A. Malcevschi, N. Marmiroli, R. Aert, G. Volckaert, J. Rueda, R. Linacero, A. Vazquez, and A. Karp. 1997. Reproducibility testing of RAPD, AFLP and SSR markers in plants by a network of European laboratories. Mol. Breed. 3:381-390.

Jubrael, J.M.S., S.M. Udupa, and M. Baum. 2005. Assessment of AFLP-based genetic relationships among date palm (Phoenix dactylifera L.) varieties of Iraq. J. Amer. Soc. Hort. Sci. 130:442-447.

Kim, D.-H., D. Heber, and D.W. Still. 2004. Genetic diversity of Echinacea species based upon amplified fragment length polymorphism. Genome 47:102-111.

Morse, J.E. 1901. The new rhubarb culture. Orange Judd, New York. Nei, M. and W.H. Li. 1979. Mathematical model for studying genetic variation in terms of restriction endonuclease. Proc. Natl. Acad. Sci. USA 76:5269-5273.

Parks, E.J. and J.W. Moyer. 2004. Evaluation of AFLP in poinsettia: Polymorphism selection, analysis, and cultivar identification. J. Amer. Soc. Hort. Sci. 129:863-869.

Parks, E.J., J.W. Moyer, and J.H. Lyerly. 2006. Identification of fluorescent AFLP and SSR markers for differentiation and analysis of new guinea impatiens. J. Amer. Soc. Hort. Sci. 131:622-631.

Persson, H.A., K. Rumpunen, and L.K. Möllerstedt. 2000. Identification of culinary rhubarb (Rheum spp.) cultivars using morphological characterization and RAPD markers. J. Hort. Sci. Biotechnol. 75: 684-689.

Roy, J.K., M.S. Lakshmikumaran, H.S. Balyan, and P.K. Gupta. 2004. AFLP-based genetic diversity and its comparison with diversity based on SSR, SAMPL, and phenotypic traits in bread wheat. Biochem. Genet. 42:43-59.

Rumpunen, K. 1996. Development of selection methods and strategies for breeding of culinary rhubarb, p. 90-94. In: Report 1992-94. Department of Horticultural Plant Breeding, Swedish University of Agricultural Sciences, Balsgård, Sweden.

Schmidt, K. and K. Jensen. 2000. Genetic structure and AFLP variation of remnant populations in the rare plant Pedicularis palustrus (Scrophulariaceae) and its relation to population size and reproductive components. Amer. J. Bot. 87:678-689.

Smith, N.R., R.N. Trigiano, M.T. Windham, K.H. Lamour, L.S. Finley, X. Wang, and T.A. Rinehart. 2007. AFLP markers identify Cornus florida cultivars and lines. J. Amer. Soc. Hort. Sci. 132:9096.

Tamiru, M., H.C. Becker, and B.L. Maass. 2007. Genetic diversity in yam germplasm from Ethiopia and their relatedness to the main cultivated Dioscorea species assessed by AFLP markers. Crop Sci. 47:1744-1753.

Turner, D.M. 1938. The economic rhubarbs: A historical survey of their cultivation in Britain. J. Royal Hort. Soc. 63:355-370.

Vos, P., R. Hogers, M. Bleeker, M. Reijans, T. van de Lee, M. Hornes, A. Frijters, J. Pot, J. Peleman, M. Kuiper, and M. Zabeau. 1995. AFLP: A new technique for DNA fingerprinting. Nucleic Acids Res. 23:4407-4414.

Walkey, D.G.A. and K.A.M. Mathews. 1979. Rapid cloning propagation of rhubarb (Rheum rhaponticum) from meristem-tips in tissue culture. Plant Sci. Lett. 14:301-308.

Wang, A., M. Yang, and J. Liu. 2005. Molecular phylogeny, recent radiation and evolution of gross morphology of the rhubarb genus Rheum (Polygonaceae) inferred from chloroplast DNA trnL-F sequences. Ann. Bot. (Lond.) 96:488-498.

Zandstra, B.H. and D.E. Marshall. 1982. A grower's guide to rhubarb production. Amer. Veg. Grower 30:6, 9-10. 